British Journal of Nutrition (2022), 127, 914-926

doi:10.1017/S0007114521001483

(C) The Author(s), 2021. Published by Cambridge University Press on behalf of The Nutrition Society. This is an Open Access article, distributed under the terms of the Creative Commons Attribution-NonCommercial-NoDerivatives licence (http://creativecommons.org/licenses/by-nc-nd/4.0/), which permits non-commercial re-use, distribution, and reproduction in any medium, provided the original work is unaltered and is properly cited. The written permission of Cambridge University Press must be obtained for commercial re-use or in order to create a derivative work.

\title{
Risk factors of overweight/obesity-related lifestyles in university students: Results from the EHU12/24 study
}

\author{
Nerea Telleria-Aramburu and Marta Arroyo-Izaga* \\ Department of Pharmacy and Food Sciences, Faculty of Pharmacy, University of the Basque Country UPV/EHU, 01006 \\ Vitoria-Gasteiz, Spain
}

(Submitted 3 January 2021 - Final revision received 18 April 2021 - Accepted 30 April 2021 - First published online 6 May 2021)

\section{Abstract}

This paper investigates the prevalence and interaction of overweight/obesity-related lifestyles (specifically, examining whether subjects meet the recommended criteria), in a representative sample of university students. This study is part of the project EHU12/24, an observational crosssectional study, designed to assess the prevalence of excess body fat (BF) and major risk of developing overweight/obesity, according to a standardised protocol. In a cohort of 603 students, aged between 18 and 28 years, of the University of the Basque Country, information about meal patterns, diet quality, physical activity, sitting time, sleeping time, toxic habits and anthropometric measurements were collected. Sampling took place from February 2014 to May 2017. Binary logistic regression models adjusted for the covariates were utilised to test the association between lifestyles and risk of excess adiposity. The prevalence of overweight/obesity, according to BF percentage, was $14.4 \%$. The variables analysed related to meal pattern were associated with diet quality, and less healthy food habits were associated with other less health-related behaviours. Among men, moderate/low physical activity, breakfast skipping, non-adequate breakfast duration, number of eating occasions and eating breakfast alone/depending on the occasion were associated with excess BF, while among women, low MedDietScore, moderate/high alcohol consumption, non-adequate sleep duration, eating breakfast and lunch alone/depending on the occasion. Results suggest that certain unhealthy lifestyle behaviours coexist, interact with one another and increase the risk of overweight/obesity in this population. Sex-specific differences in risk factors of obesity have implications for interventions for primary prevention of obesity within this environment.

\section{Key words: Meal patterns: Diet quality: Lifestyles: University students: Spain}

The prevalence of obesity is increasing worldwide ${ }^{(1)}$, and nearly a third of the world population is now classified as overweight or obese ${ }^{(2)}$. This increase in obesity likely results from a complex interaction between changes in the food environment, as well as physical activity (PA), socio-economic, environmental and genetic factors ${ }^{(1)}$. In general, a substantial proportion of young adults, in particular higher education students, follow unhealthy lifestyles ${ }^{(3,4)}$, which gives cause for concern. Some studies observed that first year university students have significant weight gain ${ }^{(5)}$, followed by ongoing slow but steady increase in weight ${ }^{(6)}$. Researches among university students show overweight/obesity prevalences of approximately $30 \%$, with rates higher for men than for women ${ }^{(4,7-9)}$. In particular, the prevalence of overweight/obesity among Spanish university students is about $20 \%^{(10-12)}$.

Recent studies have found associations between overweight/ obesity among university students and certain unhealthy lifestyle such as a high preference for high-fat and high-sugar food ${ }^{(13,14)}$, a lack of PA and exercise ${ }^{(14,15)}$, shorter sleep duration and tobacco use $^{(8)}$. These lifestyle behaviours have been reported to differ by sex ${ }^{(8,16-19)}$ and living arrangement ${ }^{(18,20,21)}$ in university student populations. So, for example, diet quality is usually higher for women than for men ${ }^{(22)}$ and students living away from the parental home have poorer eating habits ${ }^{(18,20,21)}$.

Regarding diet, university student populations are widely reported to engage in unhealthy eating behaviours such as high consumption of snack foods ${ }^{(23,24)}$, high consumption of fast foods ${ }^{(24,25)}$, insufficient consumption of fruit and vegetables $^{(23,26)}$ and shift from traditional healthy diets (i.e. the Mediterranean Diet) to more unhealthy eating patterns ${ }^{(27)}$. These eating behavioural characteristics are associated with the risk of overweight/obesity. However, in this sense, beyond what to eat, where, when, how and with whom we eat are important too because not only the volume of foods but also the type and variety of foods consumed affect overweight/obesity risk ${ }^{(28)}$. All these characteristics of diet are part of the term 'meal pattern' and have an important role in total energy intake and therefore in the regulation of adiposity and

Abbreviations: BF, body fat; EO, eating occasion; HEI, Healthy Eating Index; MDS, MedDietScore; SDU, standard drink units.

* Corresponding author: Marta Arroyo-Izaga, email marta.arroyo@ehu.eus 
body weight ${ }^{(29)}$; however, to date, no studies have evaluated the influence of meal pattern on overweight/obesity risk in university student populations.

Behaviour acquired during young adulthood, including the stage of university studies, often lasts into adulthood ${ }^{(30)}$. Therefore, this stage of life is considered a critical period to instil positive dietary and health behaviours to promote optimal health, as well as to prevent immediate health problems, such as obesity ${ }^{(31)}$, and long-term health problems, such as CVD ${ }^{(32)}$. Moreover, an inadequate meal pattern (e.g. characterised by no breakfast and/or the replacement of lunch with snacks) can make feel as if there are not getting enough nutrients from diet, which might be a motivation to use dietary supplements for health benefits ${ }^{(33)}$. Additionally, to weight loss and to obtain beauty benefits, especially in females, and to build muscle in males are factors that also lead to dietary supplement use in university students ${ }^{(33)}$. Several studies have estimated that more than half of university students use dietary supplements ${ }^{(34,35)}$, with the consequent risk of adverse effects, in particular when they are taken without a prescription ${ }^{(34)}$.

Until now, the majority of studies have focused on a single or a few health lifestyle behaviours, even though research has shown that health behaviours often coexist, interact and increase the likelihood of multiplicative illnesses in university students ${ }^{(3,36,37)}$. Thus, the interactions among lifestyles related to obesity are poorly understood in this population. To our knowledge, no previous studies have analysed multiple overweight/obesity-related lifestyles, focus on the whole lifestyle rather, than a single or a few lifestyle behaviours, in university students.

The aim of the present study was therefore to investigate the prevalence and interactions of overweight/obesity-related lifestyles (specifically, examining whether subjects meet the recommended criteria), in a representative sample of students at a Spanish university, in order to identify the best strategies to combat obesity within this population. These strategies could take advantage of the naturally occurring opportunities offered by this stage of life (i.e. young adult) to induce behaviour changes. In addition, university students are likely to constitute a significant proportion of the socio-economic elite of the future; thus, their habits and behaviours are most likely to become the norm ${ }^{(38)}$, rendering this population interesting to investigate. Based on the literature data ${ }^{(3,8,16-21,36,37)}$, the following hypotheses were raised: unhealthy lifestyles coexist, interact and increase the risk of overweight/obesity in this population and these effects vary by sex and living arrangement.

\section{Subjects and methods}

This study is component of the EHU12/24 project, which is an observational cross-sectional study designed to assess the prevalence of excess body fat (BF) and major risk of developing overweight/obesity, following a standardised protocol and involving a representative sample of the UPV/EHU student population ${ }^{(39)}$. The design, sampling and procedures of the EHU12/24 have been described in detail elsewhere ${ }^{(39)}$.

\section{Study population}

Briefly, EHU12/24 project was conducted from February 2014 to May 2017 on a cohort of 603 university students (59.5\% women) aged between 18 and 28 years (with an average age of $20 \cdot 9(2 \cdot 1)$ years). Participants were recruited using a randomised, multistage, conglomerate procedure and stratified by knowledge area (arts and humanities, sciences, health sciences, social and legal sciences, and engineering and architecture), age and sex. First, a computer randomly selects the subjects according to their knowledge areas and age, and then the subjects are distributed by sex in each knowledge area. Moreover, we assigned a weight to each participant such as that the computed statistics based on the gathered data could be more representative of the population from which the data were retrieved.

In total, 696 of the 1300 students who were invited to participate in the study gave their consent and participated, resulting in a response rate of $53.5 \%$. To be valid for inclusion in the data analysis, the questionnaire (face-to-face) and anthropometry measurements were required. This requirement was met by 603 study participants, accounting for $46.4 \%$ of all participants invited to participate in the research. Participants with missing data were excluded from the study.

The study was conducted according to the guidelines laid down in the Declaration of Helsinki, and all procedures involving human subjects/patients were approved by the Ethical Committee on Human Research of the UPV/EHU (CEISH/193/ 2013/ARROYO IZAGA). Written informed consent was obtained from all subjects/patients.

The following eligibility criteria for inclusion were established to recruit a healthy population: (1) Caucasian adults (majority ethnic group in this population) aged between 18 and 28 years; (2) no current reported diseases, except for overweight/obesity (the participants could have excess BF), or conditions (such as being an athlete) that may affect the weight, height, frame size and/or body composition; (3) no relation to other participants and (4) in the case of female students, no pregnancy or breast-feeding.

\section{Body measurements and other characteristics}

A well-trained anthropometrist performed all measurements following the ISAK protocols ${ }^{(40)}$. The anthropometrical measurements analysed included the following skinfold thicknesses: bicipital, tricipital, subscapular and suprailiac. Body density was calculated from the sum of the average skinfold thicknesses at each site by using the equations of Durnin \& Womersley ${ }^{(41)}$. The Siri-age-sex equation ${ }^{(42)}$ was used to convert density to percentage of BF (BF\%). Each subjects' BF\% was classified using the criteria proposed by Bray et al. ${ }^{(43)}$. In addition, data related to the place of habitual residence, responsibility for shopping and cooking were recorded using the questionnaires developed by Bennassar ${ }^{(44)}$ and St. Jeor ${ }^{(45)}$. Responsibility for shopping and cooking was multiple-answers questions.

\section{Diet intake assessment}

Diet was assessed using a face-to-face interview that includes: two meal pattern questionnaires based on validated forms ${ }^{(44,45)}$, 
and a short FFQ that is a modified and validated version ${ }^{(46)}$. The first of them was a participant-identified approach ${ }^{(47)}$ used to define eating occasions (EO), in which the participants were asked to describe how they usually ate on an 'ordinary' day, specifying time for meal, meal duration and choosing the type of meal best corresponding to their own meal. Two different meal types were defined: main meal and light meal/snack meal. The aim was to identify all EO, even those consisting only of a drink. In the instructions, subjects were reminded to include snacks and other light meals and that they could have several main meals during a day. All types of meals were referred to as 'meals' in the text. From data on time for meal and meal duration, number of EO per day and spacing of EO (mean time between meals, i.e. breakfast, lunch and dinner) were calculated. This questionnaire also included information on the presence of others at a meal (eat alone $v$. with others or depending on the occasion).

The second meal pattern questionnaire was a time-of-day approach $^{(47)}$ and was used to describe frequency of EO (less than weekly, 1-2 times/week, 3-4 times/week, 5-6 times/week, every day). This approach defines meals according to the timeof-day in which food was consumed. Explicitly, a 'meal' has been defined as the largest EO (breakfast, lunch and dinner), with smaller EO considered as light meals/snack meals (mid-morning, afternoon, after dinner and mid-night snacks).

A meal pattern score, incorporating the eight variables studied in this section (number of EO per day; interval between meals; breakfast skipping; eating breakfast, lunch and dinner alone $v$. with others; breakfast duration; and lunch/dinner duration) and assigning a score (from 0 to 1 ) to each one, was constructed. We used as a model two scores designed previously by other authors ${ }^{(48,49)}$. Each variable of the present score was compared with the established recommendations to prevent overweight/obesity, when these were available, or on current evidence in the general population. Detailed information on the operationalisation of our score can be found in Table 1 . The total meal pattern score ranged from 0 to 8 , with higher scores indicating greater concordance with the recommendations.

In the short FFQ, the students were first asked whether they consume each specific item. If the participants affirmed consumption, they were asked about the usual frequency of consumption (daily, weekly or monthly) of one standard serving ${ }^{(63)}$. The daily intakes of each food item were determined based on the average consumption frequency and the amount of each food item consumed. For items that included several foods, each food's contribution was estimated with weighting coefficients obtained from the usual consumption data ${ }^{(64)}$. Additionally, an open question was added with the objective of identifying foods that were not included in the short FFQ, such as soya products. When a food was written in the open questionnaire, we also asked how often they consumed it.

All food items that were consumed were entered into DIAL for Windows ${ }^{(65)}$, a type of dietary assessment software, to estimate energy and nutrient intake (these results are part of an article under revision; unpublished results). From the data obtained on food groups, energy and nutrient intake, adherence to food-based dietary guidelines was evaluated. For this end, we used two diet quality indices: the Healthy Eating Index-2010 $\left(\right.$ HEI-2010) ${ }^{(56)}$ and the MedDietScore (MDS) ${ }^{(66)}$. The former index is a measure of diet quality used to assess how well a set of food items aligns with key recommendations of the Dietary Guidelines for Americans. Although specific to US dietary guidelines, the HEI-2010 has been widely used in European populations and even in studies involving European university students ${ }^{(67)}$ which allows us to compare results. We used HEI-2010 instead of HEI-2015 for many reasons. First, HEI-2010 has been applied previously with UPV/EHU students and with other university student populations ${ }^{(67)}$, which allows us to establish comparisons with these data sets. A second reason is that HEI-2010 includes assessment of alcohol consumption (within the 'empty calories' component), while HEI-2015 does not include it. The HEI-2010 consists of twelve components, including nine on adequacy and three on moderation that are scored per $1000 \mathrm{kcal}$. The theoretical range of the HEI-2010 is from 0 to 100 . We scored data with the simple HEI-scoring algorithm method.

The other quality index used, the MDS is an index that estimates the level of adherence to the MD pattern and is associated with biomarkers of CVD risk ${ }^{(57)}$. This score has eleven main components; each was scored separately but not by energy. For the consumption of foods considered to deviate from this dietary pattern, the scores were assigned on a reverse scale (scores 5 to 0 ). The total score (sum) ranges between 0 and 55 . Higher values of this score indicate greater adherence to the MD pattern. These two diet quality indices were incorporated into the meal pattern score to construct the diet total score (Table 1). The weight of each index was estimated taking into account the number of items within each one (HEI-2010 consists of twelve components and MDS of eleven).

\section{Lifestyle (different from diet)}

The PA (type of activity, d/week and time/d) and sedentary behaviours (time spent sitting) related data were registered through the International Physical Activity Questionnaire in its short-form version $^{(58)}$. Results of PA were analysed according to the International Physical Activity Questionnaire scoring protocol ${ }^{(58)}$ that establishes three categories (low, moderate and high).

The self-reported sleep duration per night was ascertained by the following question: 'On an average school night, how many hours of sleep do you get?'(68). In addition, information about alcohol consumption was registered using the questions from the National Health Survey ${ }^{(68)}$. Moreover, the short FFQ included specific questions about the frequency of intake of alcoholic beverages: beer, wine, cider, aperitif with alcohol and liquor. The alcohol consumption data are expressed as grams of alcohol and standard drink units (SDU) per week $^{(69)}$. In the present study, we used the SDU defined for Spain (one SDU is equivalent to $10 \mathrm{~g}$ of alcohol). With this information, the participants were categorised into abstemious, moderate consumption and high consumption categories according to the Spanish Society of Community Nutrition criteria, which considers moderate drinking up to one SDU per d for women and up to two SDU per d for men ${ }^{(61)}$.

A lifestyle score, incorporating the five analysed variables in this section, was constructed (Table 1). Established risk factors of 
Table 1. Diet and lifestyle score construction

\begin{tabular}{|c|c|c|c|}
\hline Score & Variables & Operationalisation & Scoring (point) \\
\hline \multirow{24}{*}{ Meal pattern (0-8 points) } & \multirow{3}{*}{ No. of EO per $d^{(50)}$} & Adequate $(5-7 \mathrm{EO} / \mathrm{d})$ & 1 \\
\hline & & Barely adequate $(3-4 \mathrm{EO} / \mathrm{d})$ & 0.5 \\
\hline & & Inadequate $(<3$ or $>7 \mathrm{EO} / \mathrm{d})$ & 0 \\
\hline & \multirow[t]{3}{*}{ Interval between meals ${ }^{(50)}$} & Adequate $(120-210 \mathrm{~min})$ & 1 \\
\hline & & Barely adequate $(210-300 \mathrm{~min})$ & 0.5 \\
\hline & & Inadequate $(<120$ or $>300 \mathrm{~min})$ & 0 \\
\hline & \multirow[t]{3}{*}{ Breakfast skipping ${ }^{(51)}$} & Never (eating breakfast 5-7 d/week) & 1 \\
\hline & & Sometimes (eating breakfast 3-4 d/week) & 0.5 \\
\hline & & Daily or almost daily (eating breakfast $\leq 2 \mathrm{~d} /$ week) & 0 \\
\hline & \multirow{3}{*}{ Eating breakfast alone $v$. with others ${ }^{(52)}$} & With others & 1 \\
\hline & & Depending on the occasion & 0.5 \\
\hline & & Always alone* & 0 \\
\hline & \multirow[t]{3}{*}{ Eating lunch alone $v$. with others ${ }^{(53)}$} & With others & 1 \\
\hline & & Depending on the occasion & 0.5 \\
\hline & & Always alone & 0 \\
\hline & \multirow[t]{3}{*}{ Eating dinner alone $v$. with others ${ }^{(53)}$} & With others & 1 \\
\hline & & Depending on the occasion & 0.5 \\
\hline & & Always alone & 0 \\
\hline & \multirow[t]{3}{*}{ Breakfast duration $^{(54,55)}$} & Adequate ( $\geq 15 \mathrm{~min})$ & 1 \\
\hline & & Barely adequate ( $\geq 7$ and $<15 \mathrm{~min}$ ) & 0.5 \\
\hline & & Inadequate (<7 min) & 0 \\
\hline & \multirow[t]{3}{*}{ Lunch/dinner duration ${ }^{(55)}$} & Adequate $(\geq 30 \mathrm{~min})$ & 1 \\
\hline & & Barely adequate ( $\geq 15$ and $<30 \mathrm{~min}$ ) & 0.5 \\
\hline & & Inadequate (<15 min) & 0 \\
\hline \multirow{6}{*}{$\begin{array}{l}\text { Diet total (Meal pattern score }+ \\
\text { HEI-2010 + MDS) (0-31 points) }\end{array}$} & \multirow{3}{*}{ HEI-2010, classification ${ }^{(56)}$} & Good (score > 80) & 12 \\
\hline & & Need improvement (score 51-80) & 6 \\
\hline & & Poor (score <51) & 0 \\
\hline & \multirow{3}{*}{ MDS, classification ${ }^{(57)}$} & High adherence $(>35)$ & 11 \\
\hline & & Intermediate adherence $(\geq 18$ and $\leq 34)$ & 5.5 \\
\hline & & Low adherence (0-18) & 0 \\
\hline \multirow{12}{*}{ Lifestyle (0-3 points) } & \multirow{3}{*}{ PA level(58) } & High & 1 \\
\hline & & Moderate & 0.5 \\
\hline & & Low & 0 \\
\hline & \multirow[t]{3}{*}{ Sitting time ${ }^{(59,60)}$} & Adequate $(\leq 3.3 \mathrm{~h} / \mathrm{d}) \dagger$ & 1 \\
\hline & & Barely adequate $(>3.3$ and $\leq 7.5 \mathrm{~h} / \mathrm{d})$ & 0.5 \\
\hline & & Inadequate $(>7.5 \mathrm{~h} / \mathrm{d})$ & 0 \\
\hline & \multirow[t]{3}{*}{ Alcohol consumption ${ }^{(49,61)}$} & Abstemious & 0.5 \\
\hline & & Moderate consumption & 0.25 \\
\hline & & High consumption & 0 \\
\hline & \multirow[t]{3}{*}{ Sleep duration per night ${ }^{(49,62)}$} & Adequate $(7-8 \mathrm{~h} / \mathrm{d})$ & 0.5 \\
\hline & & Barely adequate $(6-7$ or $8-10 \mathrm{~h} / \mathrm{d})$ & 0.25 \\
\hline & & Inadequate $(<6$ or $>10 \mathrm{~h} / \mathrm{d})$ & 0 \\
\hline
\end{tabular}

EO, eating occasions; HEl-2010, Healthy Eating Index-2010; MDS, MedDietScore; No., number; PA, physical activity.

* In the case of participants who skipped breakfast $>4 \mathrm{~d} /$ week, the score assigned to have breakfast alone or with others and to length of breakfast was 0 .

† We used the cut-off of $\leq 3.3 \mathrm{~h} / \mathrm{d}$ of sitting time on the basis of studies suggesting that longer duration incurred a greater risk of CVD.

obesity (PA level and time spent sitting) were given more points on the score than emerging risk factors ${ }^{(70,71)}$. We have not included smoking habit in the lifestyle score because the relationship between smoking and obesity is confusing ${ }^{(72,73)}$. The total score ranged from 0 to 3 , with higher scores indicating greater concordance with the recommendations. Finally, a healthy lifestyle score derived from the diet total score and the lifestyle score was estimated. This last score ranged from 0 to 34 points, with the higher score reflecting adherence to lifestyles recommendations.

\section{Statistical analysis}

The data were analysed using SPSS for Windows (version 22.0, SPSS Inc.) and are reported as the mean values, standard deviation (SD) and frequencies. All analyses were conducted separately for male and female students because of their differences in lifestyle behaviours ${ }^{(19)}$. All the results were weighted to ensure representativeness of the UPV/EHU university students' population using weighting coefficients provided by the list of students enrolled in $2012 / 2013^{(74)}$. The symmetry of the distribution of the continuous variables was determined by a Kolmogorov-Smirnov-Lilliefors test. Differences in variables were assessed with the KruskalWallis H-test and associations between scores and indices with Spearman's correlations (the variables were not normally distributed, even after logarithmic transformation, due to data being weighted and the large sampling size; thus, small deviations rendered the variables not normally distributed). Categorical variables were analysed using $\chi^{2}$ tests. 
Finally, to analyse the possible associations between the variables of the healthy lifestyle score and risk of excess adiposity, binary logistic regressions adjusted to age and daily energy intake were performed. The $95 \%$ CI were calculated and Wald's test used for comparison of the OR. All the variables of the healthy lifestyle score were dichotomised considering, on the one hand, the healthiest category and, on the other, the intermediate and the least healthy; except for 'sitting time' variable in which the categories were: adequate + barely adequate $v$. inadequate, because the frequency for the healthiest category was very low. All tests were two-tailed, and $P$-values $<0.05$ were considered statistically significant.

\section{Results}

Regarding to BF classification results, $14.4 \%$ of the target population was classified as excessive, the prevalence of excessive BF being higher in men $(16 \cdot 1 \%)$ than in women $(13.3 \%)(P<0 \cdot 001)$. On the other hand, the percentage of students who resided with parents was $53.2 \%$. Concerning the person responsible for food shopping and cooking, more than half of the students indicated that their parents were responsible people, $56 \%$ for food shopping and $53.3 \%$ for food cooking. There were sex differences in the last three analysed variables, being higher the percentage of women who lived with parents than in men $(61.5 \% v .47 .5 \%, P<0.001)$. However, women were more likely than men to be the person responsible for buying and preparing food $(36.6 \% v .34 \cdot 0 \%$ for food shopping; and $38.3 \% v .35 .8 \%$ for food cooking; $P<0.001$ in both variables).

Diet and lifestyle (different from diet) characteristics by sex are shown in online Supplementary Table S1. Compliance with dietary recommendations in the studied population, according to sex, is described in Table 2. Between 40.3 and $50 \cdot 1 \%$ of the participants had an adequate number of EO daily, interval between meals, time spent on breakfast and/ or lunch/dinner. Sex differences were found for all these variables analysed. The percentage of men who had an adequate number of EO daily, interval between meals and never skipped breakfast was higher than in women, whereas women showed a significantly higher adequacy of time spent on breakfast and on lunch/dinner compared with men $(P<0 \cdot 001)$.

In addition, there was a significant correlation between the meal pattern score and HEI-2010 (Spearman' rho, 0.145, $P<0.001$ for the total sample; $0 \cdot 161, P<0.001$ for women; and $0.114, P<0.001$ for men), and between the meal pattern score and MDS (Spearman' rho, 0.096, $P<0.001$ for the total sample; $0 \cdot 149, P<0.001$ for women; and $0.089, P<0.001$ for men). Along these lines, the average scores for MDS and HEI2010 were higher in subjects who meet the recommendations for each of the variables of meal pattern score $v$. those who did not (online Supplementary Table S2). In addition, the average scores for meal pattern and the diet total score were higher in students who did not live with parents than in those who live with them (meal pattern score: 'living with parents' 5.4 (1.1), 'living with others' $5.5(1.4), P<0 \cdot 001$; diet total score; 'living with parents' $20 \cdot 7$ (4.8), 'living with others' $21.0(4.7)$, $P<0 \cdot 001)$.

Results of compliance with lifestyle (different from the diet) recommendations in the target population are presented in Table 3. Students were characterised by having a moderate PA level, an inadequate time spent sitting, being moderate drinkers and having an adequate time spent sleeping. The percentage of men who had a high PA level and a moderate consumption of alcohol was higher than women $(P<0.001)$, and the average lifestyle score was higher in men than women $(P<0.001)$, whereas women showed a significantly higher adequacy of time spent sleeping compared with men $(P<0 \cdot 001)$. Regarding smoking habits, $81.7 \%$ were non-smokers/ex-smokers, the proportion of non-smokers/ex-smokers being higher for men than for women $(86.9 v .78 .1 \%, P<0.001)$.

Positive and significant correlations were found between the diet total score and the lifestyle score in the total sample (Spearman' rho $=0.096, P<0.001$ ), as well as in both sexes (men, rho $=0.209, \quad P<0.001 ;$ and women, $r h o=0.105$, $P<0.001)$. The analysis of contingency tables between variables of the diet total score and the lifestyle score showed that students who meet the recommendations related to number of EO daily were more likely to have a high PA level $\left(\chi^{2}=413.6, \quad P<0.001\right)$, prolonged sitting times $\left(\chi^{2}=82.6\right.$, $P<0.001)$, moderate intakes of alcohol $\left(\chi^{2}=301.7\right.$, $P<0.001)$ and be non-smokers $\left(\chi^{2}=263.2, P<0.001\right)$. And those who meet the recommendations for the interval between meals and for time spent on breakfast were more likely to have a high PA level $\left(\chi^{2}=45 \cdot 0, P<0.001\right.$ and $\chi^{2}=43 \cdot 6, P<0 \cdot 001$, respectively) and an optimal sleep duration $\left(\chi^{2}=593.5\right.$, $P<0.001$ and $\chi^{2}=352.4, P<0.001$, respectively).

The mean score of the healthy lifestyle score for the total sample was $22 \cdot 2(4 \cdot 8)$, being higher in women than in men (22.7 (4.9) $v .21 \cdot 3(4 \cdot 5), P<0 \cdot 001)$. In addition, subjects with non-excess BF had a higher average score on the healthy lifestyle than those with excess BF (22.4 (4.7) v. 21.3 (5.0), $P<0.001)$. Dividing the population, according to $\mathrm{BF} \%$ classification, there were differences in favour of those who did not have excessive BF in adequacy of number of EO daily, interval between meals and time spent on breakfast $(P<0 \cdot 001)$ (Table 4$)$. On the other hand, people without excess BF had higher PA level, lower consumption of alcohol, a higher adequacy of sleep duration than those with excess BF $(P<0.001)$ (Table 5). Analysis of lifestyle according to $\mathrm{BF}$ by sexes showed similar results, except for PA level, adequacy of recommendations for sitting time and the average lifestyle score among women. In relation to smoking habit, the percentage of men smokers with excessive $\mathrm{BF} \%(17 \cdot 3 \%)$ was higher than those without excessive $\mathrm{BF}$ $(12.6 \%)(P<0.001)$, whereas the opposite happened in women smokers $(22 \cdot 2 \%$ with normal BF\% v. $20 \cdot 1 \%$ with excessive $\mathrm{BF} \%, P=0.03$ ).

The proportion of students with excessive BF\% who did not live with parents was higher than those who live with parents, although the differences were not significant $(14.7 \% v$. $14.2 \%, P=0 \cdot 28)$. Among men, the following variables were associated with excess BF (from largest to smallest magnitude of effect in the model 2): a moderate/low PA level (OR: $3.77, P<0.001$ ), breakfast skipping (OR: 3.66, $P<0.001$ ), a 
Table 2. Compliance with dietary recommendations by sex in the population under study: students of the University of the Basque Country (UPV/EHU), EHU12/24 study

(Mean values and standard deviations, percentages)

\begin{tabular}{|c|c|c|c|c|}
\hline \multirow{3}{*}{ No. of EO daily, \% } & \multirow{2}{*}{$\frac{\text { Total }(n 26165)}{\text { Mean or } \%}$} & \multirow{2}{*}{$\frac{\text { Men }(n 10607)}{\text { Mean or \% }}$} & \multirow{2}{*}{$\frac{\text { Women }(n 15558)}{\text { Mean or } \%}$} & \multirow[b]{2}{*}{$P^{\star}$} \\
\hline & & & & \\
\hline & & & & \\
\hline Adequate & $50 \cdot 1$ & 50.5 & 49.8 & \\
\hline Barely adequate & 48.9 & $48 \cdot 3$ & $49 \cdot 3$ & \\
\hline Inadequate & 1.0 & 1.1 & 0.9 & 0.04 \\
\hline \multicolumn{5}{|l|}{ Interval between meals, $\%$} \\
\hline Adequate & 41.0 & 41.4 & $40 \cdot 6$ & \\
\hline Barely adequate & $46 \cdot 6$ & $45 \cdot 4$ & 47.4 & \\
\hline Inadequate & 12.4 & $13 \cdot 2$ & $12 \cdot 0$ & 0.001 \\
\hline \multicolumn{5}{|l|}{ Breakfast skipping, \% } \\
\hline Never & $90 \cdot 7$ & 91.9 & 89.9 & \\
\hline Sometimes & $5 \cdot 2$ & 5.7 & 4.9 & \\
\hline Daily or almost daily & 4.0 & $2 \cdot 4$ & $5 \cdot 1$ & $<0.001$ \\
\hline \multicolumn{5}{|c|}{ Eating breakfast alone $v$. with others, $\%$} \\
\hline With others & 22.5 & 14.3 & $28 \cdot 0$ & \\
\hline Depending on the occasion & $16 \cdot 4$ & 13.5 & $18 \cdot 3$ & \\
\hline Always alone & $61 \cdot 2$ & $72 \cdot 2$ & $53 \cdot 7$ & $<0.001$ \\
\hline \multicolumn{5}{|l|}{ Eating lunch alone $v$. with others, \% } \\
\hline With others & 65.5 & 62.9 & $67 \cdot 4$ & \\
\hline Depending on the occasion & 16.9 & 13.7 & 19.1 & \\
\hline Always alone & 17.6 & 23.5 & 13.5 & $<0.001$ \\
\hline \multicolumn{5}{|l|}{ Eating dinner alone $v$. with others, \% } \\
\hline With others & $76 \cdot 1$ & 71.9 & 79.0 & \\
\hline Depending on the occasion & $12 \cdot 0$ & 14.2 & $10 \cdot 4$ & \\
\hline Always alone & 11.9 & $13 \cdot 9$ & 10.5 & $<0.001$ \\
\hline \multicolumn{5}{|l|}{ Breakfast duration, classification, \% } \\
\hline Adequate & $40 \cdot 3$ & 38.2 & 41.9 & \\
\hline Barely adequate & 39.7 & 38.4 & $40 \cdot 6$ & \\
\hline Inadequate & $20 \cdot 0$ & 23.5 & 17.5 & $<0.001$ \\
\hline \multicolumn{5}{|c|}{ Lunch/dinner duration, classification, \% } \\
\hline Adequate & $42 \cdot 2$ & 35.4 & 46.9 & \\
\hline Barely adequate & $55 \cdot 6$ & $62 \cdot 0$ & $51 \cdot 3$ & \\
\hline Inadequate & 2.2 & 2.6 & 1.9 & $<0.001$ \\
\hline \multicolumn{5}{|l|}{ HEI-2010, classification, \%† } \\
\hline Good & 24.6 & $19 \cdot 4$ & $28 \cdot 2$ & \\
\hline Needs improvement & $75 \cdot 4$ & $80 \cdot 6$ & 71.8 & $<0.001$ \\
\hline \multicolumn{5}{|l|}{ MDS, classification, \% } \\
\hline High adherence & 43.5 & 37.1 & 47.9 & \\
\hline Intermediate adherence & $56 \cdot 4$ & $62 \cdot 7$ & $52 \cdot 1$ & \\
\hline Low adherence & 0.1 & 0.2 & - & $<0.001$ \\
\hline Meal pattern scoreł ( $0-8$ points) & & & & $<0.001$ \\
\hline Mean & 5.5 & $5 \cdot 3$ & 5.6 & \\
\hline SD & 1.2 & 1.2 & 1.2 & \\
\hline Diet total score§ (0-31 points) & & & & $<0.001$ \\
\hline Mean & $20 \cdot 8$ & $20 \cdot 0$ & 21.4 & \\
\hline SD & 4.7 & 4.4 & 4.8 & \\
\hline
\end{tabular}

EO, eating occasions; No., number; HEI-2010, Healthy Eating Index; MDS, MedDietScore.

${ }^{*}$ Sex differences.

† None of the participants was classified as poor ( $<51$ points).

$\ddagger$ Meal pattern score included the following variables: no. of EO daily, interval between meals, breakfast skipping, time spent on breakfast and time spent on meals.

$\S$ Diet total score: meal pattern score + HEl-2010+ MDS.

non-adequate breakfast duration (OR: $1.58, P<0 \cdot 001)$ and number of $\mathrm{EO}$ (OR: $1.43, P<0.001$ ), and eating breakfast alone or depending on the occasion (sometimes alone/sometimes with others) (OR: 1.37, $P<0 \cdot 001$ ) (Table 6). Among women, a low MDS, a moderate/high alcohol consumption (OR: $2 \cdot 23, P<0 \cdot 001$ ), a non-adequate sleep duration (OR: $1 \cdot 72, P<0.001$ ), eating breakfast and lunch alone or depending on the occasion were associated with excess BF (variables ordered from largest to smallest magnitude of effect) (OR: 1.47, $P<0.001$; OR: 1.42, $P<0.001$, respectively) (Table 6).

\section{Discussion}

In this representative sample of university students, the prevalence of overweight/obesity, according to BF\%, was $14.4 \%$, which was lower than in other studies involving university students ${ }^{(4,7-12)}$, but higher than those from Basque Health Survey ${ }^{(75)}$. It should be noted that our study compared with those mentioned formerly used $\mathrm{BF} \%$ as diagnostic criteria to identify cases with overweight/obesity, and thus, the results between the studies are not directly comparable. In agreement with results of the Italian ${ }^{(76)}$ and other Spanish university 
Table 3. Compliance with lifestyle (different from diet) recommendations by sex in the population under study: students of the University of the Basque Country (UPV/EHU), EHU12/24 study

(Mean values and standard deviations, percentages)

\begin{tabular}{|c|c|c|c|c|}
\hline & $\begin{array}{c}\text { Total } \\
(n 26165)\end{array}$ & $\begin{array}{c}\text { Men } \\
(n 10607)\end{array}$ & $\begin{array}{c}\text { Women } \\
(n 15558)\end{array}$ & \\
\hline & Mean or $\%$ & Mean or \% & Mean or \% & $P^{\star}$ \\
\hline \multicolumn{5}{|l|}{ PA level, \% } \\
\hline High & $24 \cdot 1$ & $40 \cdot 7$ & $12 \cdot 7$ & \\
\hline Moderate & $59 \cdot 9$ & $51 \cdot 5$ & $65 \cdot 8$ & \\
\hline Low & $16 \cdot 0$ & $7 \cdot 8$ & 21.5 & $<0.001$ \\
\hline \multicolumn{5}{|c|}{ Sitting time, classification, $\%$} \\
\hline Adequate & $0 \cdot 8$ & $1 \cdot 2$ & 0.6 & \\
\hline $\begin{array}{l}\text { Barely } \\
\text { adequate }\end{array}$ & $48 \cdot 0$ & $46 \cdot 9$ & $48 \cdot 8$ & \\
\hline Inadequate & $51 \cdot 1$ & 51.9 & $50 \cdot 6$ & $<0.001$ \\
\hline \multicolumn{5}{|c|}{ Alcohol consumption, classification, $\%$} \\
\hline Abstemious & $15 \cdot 3$ & $14 \cdot 2$ & $16 \cdot 1$ & \\
\hline Moderate & $58 \cdot 6$ & $72 \cdot 7$ & $49 \cdot 0$ & \\
\hline High & $26 \cdot 0$ & $13 \cdot 1$ & $34 \cdot 8$ & $<0.001$ \\
\hline \multicolumn{5}{|c|}{ Sleep duration per night, classification, $\%$} \\
\hline Adequate & $62 \cdot 0$ & $61 \cdot 1$ & $62 \cdot 6$ & \\
\hline $\begin{array}{l}\text { Barely } \\
\text { adequate }\end{array}$ & $33 \cdot 8$ & $33 \cdot 5$ & $34 \cdot c$ & \\
\hline Inadequate & $4 \cdot 2$ & $5 \cdot 3$ & $3 \cdot 4<0$ & \\
\hline \multicolumn{5}{|c|}{ Lifestyle score (0-3 points) } \\
\hline Mean & 1.4 & 1.5 & \multirow{2}{*}{\multicolumn{2}{|c|}{$\begin{array}{c}1.3<0.001 \\
0.5\end{array}$}} \\
\hline SD & 0.5 & 0.5 & & \\
\hline
\end{tabular}

PA, physical activity

* Sex differences.

students ${ }^{(37)}$, we registered a higher prevalence of excessive BF in men than in women $(P<0 \cdot 001)$.

Concerning the meal patterns, nearly half of the target population had an adequate number of EO daily, spacing of EO and meal duration. The average scores for meal pattern and diet total were higher than the mean value of these scales $(5.5$ out of 8 and $20 \cdot 8$ out of 31 , respectively). Surprisingly, a high meal pattern and the diet total score were obtained in students who did not live with parents than those who do. However, other authors observed that students who live with their parents have healthier eating habits than those living on-campus ${ }^{(21)}$. Some studies have suggested that different meal patterns are related to overall diet quality, with the most consistent finding being an inverse relationship between breakfast skipping and diet quality ${ }^{(47)}$. Although little research has looked at the how other variables of meal pattern influence diet quality, the findings in this work showed that all variables of the meal pattern score were associated with diet quality. A possible explanation for these results is that probably a better meal pattern implies a higher food variety and dietary diversity, together with a higher choice of healthy foods than empty foods and therefore, a higher diet quality.

On the other hand, UPV/EHU female students followed more adequate dietary habits than men, taking more time on meals, eating generally with others and having a higher quality of diet. These results are consistent with findings reported in previous studies ${ }^{(22)}$ and probably related to the fact that women were generally more prone than men to make conscious efforts to try to eat a healthy diet ${ }^{(77)}$. On the other hand, male students of the present study were more likely to have an adequate interval between meals, as well as an adequate number of $\mathrm{EO} / \mathrm{d}$ and too usually eat breakfast, as compared with women. The sex differences in the interval between meals could be related to discrepancies in the distribution of energy intake throughout the day, as other authors have pointed out ${ }^{(78)}$.

In relation to lifestyles (different from diet), the population under study was characterised by having a moderate PA level, an excessive time spent sitting, being moderate drinkers and non-smokers/ex-smokers and having an adequate time spent sleeping. UPV/EHU male students had better lifestyles than women with regard to PA, drinking behaviour and smoking. However, female students presented a higher adequacy of sleeping hours compared with men $(P<0 \cdot 001)$. The sex difference observed in the PA level was similar to that of other studies ${ }^{(21,79)}$. Nevertheless, sex differences in the alcohol consumption and smoking habits were not in agreement with those previously published ${ }^{(21,80)}$. These discrepancies could be due to methodological reasons and to changes in the consumption pattern by $\operatorname{sex}^{(81)}$.

On the other hand, positive and significant correlations were found between the diet total score and the lifestyle score, with the most consistent finding being a direct relationship between an adequate number of EO daily and a high PA level, prolonged sitting times, moderate intakes of alcohol and being non-smokers; and between an adequate interval between meals and breakfast duration and a high PA level and an optimal sleep duration. These results agree with those of other authors ${ }^{(3,37)}$, who have shown that less healthy food habits are combined with a cluster of less healthy lifestyle factors (e.g. smoking, high alcohol consumption and low PA level).

In addition, subjects with excess BF had a lower average score on the healthy lifestyle scale than those with non-excess $\mathrm{BF}(P<0 \cdot 001)$. Students with excess BF were more likely to have an inadequate: number of EO daily, interval between meals and breakfast duration; omitting breakfast, eating alone, have a low score for MDS, meal pattern and diet total $(P<0.001)$. Regarding the number of EO and breakfast duration, our findings agreed with those reported by Shang et al. ${ }^{(82)}$, who showed that eating more frequently and slowly independently leads to a lower risk of overweight/obesity.

Moreover, there is strong evidence of an association between breakfast skipping and overweight/obesity, regardless of age, sex, cultural and economic conditions ${ }^{(51)}$. With respect to patterns of eating alone in relation to the risk of overweight/obesity, our results agree with the results of Lee ${ }^{(83)}$. In this sense, it should be remembered that the association of social relationships with diet quality is well characterised in the literature ${ }^{(28)}$.

Some studies have shown that, in general, people with overweight/obesity are more likely to have unhealthy lifestyles (e.g. insufficiently physically active, sedentary behaviours, binge drinking, smoking and sleeping time ${ }^{(4,84)}$. These results are consistent with the finding of our work, in which students with excess BF had a low-moderate PA level, a moderate-high consumption of alcohol, a higher sitting time and a lower time spent sleeping than those with a normal $\mathrm{BF} \%(P<0.001)$. In this study, excess $\mathrm{BF}$ has associated with different variables of the healthy lifestyle score in men than women. Among men, a moderate/low 
Table 4. Compliance with dietary recommendations according to body fat (BF) classification in the population under study: students of the University of the Basque Country (UPV/EHU), EHU12/24 study

(Mean values and standard deviations, percentages)

\begin{tabular}{|c|c|c|c|c|c|c|c|c|c|}
\hline & \multicolumn{3}{|c|}{ Total (n 26 165) } & \multicolumn{3}{|c|}{ Men (n 10 607) } & \multicolumn{3}{|c|}{ Women (n 15558$)$} \\
\hline & $\begin{array}{c}\text { Normal } \\
\text { BF\% } \\
(n 22391)\end{array}$ & $\begin{array}{c}\text { Excessive } \\
\text { BF\% } \\
(n 3375)\end{array}$ & & $\begin{array}{c}\text { Normal } \\
\text { BF\% } \\
(n 8902)\end{array}$ & $\begin{array}{c}\text { Excessive } \\
\text { BF\% } \\
(n 1705)\end{array}$ & & $\begin{array}{c}\text { Normal } \\
\text { BF\% } \\
(n 13489)\end{array}$ & $\begin{array}{c}\text { Excessive } \\
\text { BF\% } \\
(n 2069)\end{array}$ & \\
\hline & $\begin{array}{c}\text { Mean } \\
\text { or } \%\end{array}$ & $\begin{array}{l}\text { Mean } \\
\text { or } \%\end{array}$ & $P^{\star}$ & $\begin{array}{c}\text { Mean } \\
\text { or } \%\end{array}$ & $\begin{array}{c}\text { Mean } \\
\text { or } \%\end{array}$ & $P^{\star}$ & $\begin{array}{l}\text { Mean } \\
\text { or } \%\end{array}$ & $\begin{array}{c}\text { Mean } \\
\text { or } \%\end{array}$ & $P^{\star}$ \\
\hline \multicolumn{10}{|l|}{ No. of EO daily, \% } \\
\hline Barely adequate & $48 \cdot 1$ & $53 \cdot 7$ & & $45 \cdot 5$ & $63 \cdot 1$ & & $49 \cdot 9$ & 45.9 & \\
\hline Inadequate & 0.7 & $2 \cdot 4$ & $<0.001$ & 1.4 & 0.0 & $<0.001$ & 0.3 & 4.4 & $<0.001$ \\
\hline \multicolumn{10}{|l|}{ Interval between meals, \% } \\
\hline Adequate & $41 \cdot 2$ & 39.5 & & $42 \cdot 0$ & $38 \cdot 1$ & & $40 \cdot 7$ & 40.5 & \\
\hline Barely adequate & 47.9 & $38 \cdot 7$ & & $46 \cdot 6$ & $39 \cdot 3$ & & $48 \cdot 8$ & $38 \cdot 3$ & \\
\hline Inadequate & $10 \cdot 9$ & $21 \cdot 8$ & $<0.001$ & 11.4 & $22 \cdot 6$ & $<0.001$ & $10 \cdot 6$ & $21 \cdot 2$ & $<0.001$ \\
\hline \multicolumn{10}{|l|}{ Breakfast skipping, \% } \\
\hline Never & $91 \cdot 8$ & 84.5 & & $94 \cdot 2$ & $79 \cdot 8$ & & $90 \cdot 2$ & $88 \cdot 4$ & \\
\hline Daily or almost daily & $3 \cdot 8$ & $5 \cdot 2$ & $<0.001$ & $2 \cdot 2$ & 3.5 & $<0.001$ & 4.9 & $6 \cdot 7$ & 0.003 \\
\hline \multicolumn{10}{|c|}{ Eating breakfast alone $v$. with others, $\%$} \\
\hline With others & $23 \cdot 5$ & $16 \cdot 0$ & & 14.9 & $11 \cdot 0$ & & $29 \cdot 2$ & $20 \cdot 0$ & \\
\hline Depending on the occasion & $16 \cdot 2$ & $17 \cdot 6$ & & $12 \cdot 7$ & $17 \cdot 7$ & & $18 \cdot 4$ & $17 \cdot 5$ & \\
\hline Always alone & $60 \cdot 3$ & $66 \cdot 4$ & $<0.001$ & $72 \cdot 3$ & $71 \cdot 3$ & $<0.001$ & $52 \cdot 3$ & $62 \cdot 5$ & $<0.001$ \\
\hline \multicolumn{10}{|l|}{ Eating lunch alone $v$. with others, \% } \\
\hline With others & $66 \cdot 6$ & $59 \cdot 0$ & & $62 \cdot 8$ & $63 \cdot 2$ & & $69 \cdot 2$ & $55 \cdot 6$ & \\
\hline Depending on the occasion & $16 \cdot 7$ & $18 \cdot 1$ & & $14 \cdot 4$ & $9 \cdot 8$ & & $18 \cdot 2$ & 24.9 & \\
\hline Always alone & $16 \cdot 7$ & $22 \cdot 9$ & $<0.001$ & $22 \cdot 8$ & $27 \cdot 1$ & $<0.001$ & $12 \cdot 6$ & $19 \cdot 5$ & $<0.001$ \\
\hline \multicolumn{10}{|l|}{ Eating dinner alone $v$. with others, \% } \\
\hline With others & $76 \cdot 4$ & $74 \cdot 6$ & & $72 \cdot 7$ & $67 \cdot 6$ & & $78 \cdot 8$ & $80 \cdot 4$ & \\
\hline Depending on the occasion & $12 \cdot 2$ & $10 \cdot 7$ & & $14 \cdot 7$ & 11.5 & & $10 \cdot 5$ & $10 \cdot 0$ & \\
\hline Always alone & 11.4 & $14 \cdot 7$ & $<0.001$ & $12 \cdot 6$ & $20 \cdot 9$ & $<0.001$ & $10 \cdot 7$ & $9 \cdot 5$ & 0.19 \\
\hline \multicolumn{10}{|l|}{ Breakfast duration, classification, \% } \\
\hline Adequate & $40 \cdot 9$ & $37 \cdot 1$ & & $39 \cdot 8$ & $29 \cdot 9$ & & $41 \cdot 6$ & $43 \cdot 4$ & \\
\hline Barely adequate & $40 \cdot 2$ & $36 \cdot 5$ & & $37 \cdot 2$ & $44 \cdot 3$ & & $42 \cdot 2$ & $29 \cdot 6$ & \\
\hline Inadequate & $18 \cdot 9$ & $26 \cdot 4$ & $<0.001$ & $23 \cdot 0$ & $25 \cdot 8$ & $<0.001$ & $16 \cdot 1$ & $27 \cdot 0$ & $<0.001$ \\
\hline Inadequate & $2 \cdot 2$ & $2 \cdot 0$ & 0.61 & $3 \cdot 1$ & - & $<0.001$ & 1.6 & $3 \cdot 7$ & $<0.001$ \\
\hline \multicolumn{10}{|l|}{ HEI-2010 classification, \%† } \\
\hline Good & 24.9 & $22 \cdot 8$ & & $20 \cdot 6$ & 12.9 & & $27 \cdot 7$ & $30 \cdot 8$ & \\
\hline Needs improvement & $75 \cdot 1$ & $77 \cdot 2$ & 0.004 & $79 \cdot 4$ & $87 \cdot 1$ & $<0.001$ & $72 \cdot 3$ & $69 \cdot 2$ & 0.004 \\
\hline \multicolumn{10}{|l|}{ MDS classification, \% } \\
\hline High adherence & $45 \cdot 0$ & $34 \cdot 8$ & & $38 \cdot 4$ & $30 \cdot 3$ & & $49 \cdot 4$ & $38 \cdot 6$ & \\
\hline Intermediate adherence & $54 \cdot 9$ & $65 \cdot 2$ & & $61 \cdot 4$ & $69 \cdot 7$ & & $50 \cdot 6$ & $61 \cdot 2$ & \\
\hline Low adherence & $0 \cdot 1$ & - & $<0.001$ & $0 \cdot 2$ & - & $<0.001$ & - & - & $<0.001$ \\
\hline Meal pattern score $\ddagger$ (0-8 points) & & & $<0.001$ & & & $<0.001$ & & & $<0.001$ \\
\hline Mean & 5.5 & $5 \cdot 1$ & & $5 \cdot 3$ & $5 \cdot 0$ & & $5 \cdot 7$ & $5 \cdot 3$ & \\
\hline SD & $1 \cdot 2$ & 1.4 & & $1 \cdot 2$ & $1 \cdot 3$ & & $1 \cdot 2$ & 1.5 & \\
\hline Diet total score§ (0-12 points) & & & $<0.001$ & & & $<0.001$ & & & $<0.001$ \\
\hline Mean & $21 \cdot 0$ & $19 \cdot 9$ & & $20 \cdot 2$ & $18 \cdot 9$ & & $21 \cdot 5$ & $20 \cdot 8$ & \\
\hline SD & $4 \cdot 6$ & $5 \cdot 0$ & & 4.4 & $4 \cdot 1$ & & $4 \cdot 7$ & 5.5 & \\
\hline
\end{tabular}

BF, body fat; No., number; EO, eating occasions; HEI-2010, Healthy Eating Index; MDS, MedDietScore.

* Differences between normal BF and excess BF.

$\dagger$ None of the participants was classified as poor ( $<51$ points).

¥ Meal pattern score included the following variables: no. of EO daily, interval between meals, breakfast skipping, time spent on breakfast and time spent on meals. $\S$ Diet total score: meal pattern score + HEI-2010 + MDS

PA level, breakfast skipping, a non-adequate breakfast duration and number of EO and eating breakfast alone or depending on the occasion; and among women, a low MDS, a moderate/high alcohol consumption, a non-adequate sleep duration, eating breakfast and lunch alone or depending on the occasion were associated with excess BF. The largest effects (magnitudes of
ORs) were found for the variables breakfast skipping and PA level in men, and for adherence to the Mediterranean diet in women.

In general, these sex differences observed here could be due to the fact that women are more likely to find healthy eating more important ${ }^{(85)}$, and therefore, they followed more adequate 
Table 5. Compliance with lifestyle recommendations according to body fat (BF) classification in the population under study: students of the University of the Basque Country (UPV/EHU), EHU12/24 study

(Mean values and standard deviations, percentages)

\begin{tabular}{|c|c|c|c|c|c|c|c|c|c|}
\hline & \multicolumn{3}{|c|}{ Total (n 26 165) } & \multicolumn{3}{|c|}{ Men (n 10 607) } & \multicolumn{3}{|c|}{ Women (n 15 558) } \\
\hline & $\begin{array}{c}\text { Normal BF\% } \\
(n 22391) \\
\end{array}$ & $\begin{array}{c}\text { Excessive BF\% } \\
(n 3375) \\
\end{array}$ & & $\begin{array}{l}\text { Normal BF\% } \\
(n \text { 8902) } \\
\end{array}$ & $\begin{array}{l}\text { Excessive BF\% } \\
(n 1705) \\
\end{array}$ & & $\begin{array}{c}\text { Normal BF\% } \\
(n 13489) \\
\end{array}$ & $\begin{array}{c}\text { Excessive BF\% } \\
(n \text { 2069) } \\
\end{array}$ & \\
\hline & Mean or $\%$ & Mean or \% & $P^{\star}$ & Mean or \% & Mean or $\%$ & $P^{*}$ & Mean or \% & Mean or $\%$ & $P^{\star}$ \\
\hline \multicolumn{10}{|l|}{ PA level, \% } \\
\hline High & $25 \cdot 1$ & $17 \cdot 9$ & & 44.9 & $18 \cdot 6$ & & $12 \cdot 0$ & $17 \cdot 2$ & \\
\hline Moderate & $58 \cdot 6$ & $68 \cdot 2$ & & $48 \cdot 0$ & $69 \cdot 7$ & & $65 \cdot 6$ & $67 \cdot 0$ & \\
\hline Low & $16 \cdot 3$ & $13 \cdot 9$ & $<0.001$ & $7 \cdot 1$ & $11 \cdot 7$ & $<0.001$ & $22 \cdot 4$ & $15 \cdot 8$ & $<0.001$ \\
\hline \multicolumn{10}{|l|}{ Sitting time, classification, $\%$} \\
\hline Adequate & 1.0 & - & & 1.4 & - & & 0.7 & - & \\
\hline Barely adequate & $47 \cdot 8$ & $49 \cdot 1$ & & $48 \cdot 3$ & $40 \cdot 1$ & & $47 \cdot 5$ & $56 \cdot 8$ & \\
\hline Inadequate & $51 \cdot 2$ & $50 \cdot 9$ & $<0.001$ & $50 \cdot 3$ & $59 \cdot 9$ & $<0.001$ & $51 \cdot 8$ & $43 \cdot 2$ & $<0.001$ \\
\hline \multicolumn{10}{|c|}{ Alcohol consumption, classification, \% } \\
\hline Abstemious & $15 \cdot 5$ & $14 \cdot 6$ & & $13 \cdot 5$ & $17 \cdot 8$ & & $16 \cdot 8$ & $12 \cdot 0$ & \\
\hline Moderate & $59 \cdot 0$ & $56 \cdot 8$ & & 73.9 & $66 \cdot 8$ & & $49 \cdot 1$ & 48.5 & \\
\hline High & $25 \cdot 6$ & $28 \cdot 7$ & $<0.001$ & $12 \cdot 6$ & $15 \cdot 5$ & $<0.001$ & $34 \cdot 1$ & 39.5 & $<0.001$ \\
\hline \multicolumn{10}{|c|}{ Sleep duration per night, classification, $\%$} \\
\hline Adequate & $63 \cdot 3$ & $54 \cdot 2$ & & $61 \cdot 8$ & $57 \cdot 8$ & & $64 \cdot 4$ & $51 \cdot 3$ & \\
\hline Barely adequate & 32.5 & $41 \cdot 3$ & & $33 \cdot 2$ & $35 \cdot 3$ & & $32 \cdot 1$ & $46 \cdot 2$ & \\
\hline Inadequate & $4 \cdot 1$ & 4.5 & $<0.001$ & $5 \cdot 0$ & $6 \cdot 9$ & $<0.001$ & 3.5 & $2 \cdot 6$ & $<0.001$ \\
\hline Lifestyle score (0-5 points) & & & $<0.001$ & & & $<0.001$ & & & 0.001 \\
\hline Mean & 1.4 & 1.3 & & 1.6 & 1.4 & & $1.3 \dagger$ & $1.3 \dagger$ & \\
\hline SD & 0.5 & 0.5 & & 0.5 & 0.4 & & 0.5 & 0.5 & \\
\hline
\end{tabular}

PA, physical activity.

* Differences between normal BF and excess BF.

$\dagger$ Differences were found between women with normal BF\% and with excessive BF\% (1.29 (0.46); 1.33 (0.47)).

dietary habits than men, eating a greater number of EO daily, skipping fewer breakfasts, taking more time on those meals, and they had a better diet quality, as other authors have highlighted $^{(22)}$. With respect to other lifestyles such as PA, probably cultural practices and childhood habits can be associated with a higher PA level in men than women ${ }^{(86)}$.

Contrary to what one might expect, UPV/EHU men students with excess BF were more likely to have an adequate lunch/dinner duration and to be abstemious and women students with excess BF were more likely to have an adequate sitting time, a high HEI-2010 and a high PA level. These results could be related to adoption of healthy behaviours for weight loss (e.g. eating less or different food, or exercising to lose weight ${ }^{(87)}$. Contradictory results were obtained in women for the two diet quality indices estimated, this result could be related to discrepancies in constructs and scoring criteria of diet quality indices used.

The findings of the study should be considered within the context of its limitations. First, recall bias inherent in a convenience sample cannot be ruled out. The decision to participate or not may have been influenced by several factors, including social, educational and health conditions, which may again correlate with outcome risk factors. Second, self-reports of the behaviours may be subject to social desirability bias; thus, the findings may be under or overestimated. Despite that, previous validation studies indicate that the self-reported information, for example, those related to diet, is reported with sufficient accuracy for use in epidemiology analysis ${ }^{(88)}$. It should be noted that we used previously well-proven or validated questionnaires. Third, the study was based on a large survey that included a face-to-face interview and anthropometric measurements; thus, the considerable length of each assessment may have influenced answers and response rate. To avoid this, the majority of assessments were conducted over $2 \mathrm{~d}$ to ensure adequate concentration while answering the questions and to promote the participation. Finally, fourth, the design itself was cross-sectional so causal conclusions cannot be drawn from the behaviour factors selected. In future research, a cohort of students will be followed to assess what effect the university environment has on their health behaviours.

The main strength of this work compared with other studies $^{(89)}$ is that we used the $\% \mathrm{BF}$ instead of BMI as a diagnostic criterion for overweight/obesity, in order to avoid both false positives and negatives. In addition, the set of protocolised measurements used in this study generated a large amount of data regarding behavioural determinants of overweight/obesity and interrelationships among them, in a community of university students.

\section{Conclusions}

The results of this study suggest that certain unhealthy lifestyle behaviours coexist, interact and increase the risk of overweight/obesity in this population. The sex-specific differences in risk factors of excess adiposity have important implications for interventions for primary prevention of obesity within this environment. Further studies are needed to confirm the complex interconnection between underlying factors of overweight/ obesity. 
Table 6. Factors related to diet and lifestyles associated with an increased risk of excess body fat (BF) in the population under study: students of the University of the Basque Country (UPV/EHU), EHU12/24 study

(Odds ratio and $95 \%$ confidence intervals)

\begin{tabular}{|c|c|c|c|c|c|c|}
\hline \multirow[b]{2}{*}{ Variables* } & \multicolumn{3}{|c|}{ Model $1 \dagger$} & \multicolumn{3}{|c|}{ Model $2 \dagger$} \\
\hline & OR & $95 \% \mathrm{Cl}$ & $P$ & OR & $95 \% \mathrm{Cl}$ & $P$ \\
\hline \multicolumn{7}{|l|}{ Men ( $n 10607)$} \\
\hline \multicolumn{7}{|l|}{ No. of EO daily } \\
\hline Barely adequate/Inadequate & 2.08 & $1 \cdot 86,2 \cdot 32$ & $<0.001$ & 1.43 & $1.27,1.61$ & $<0.001$ \\
\hline \multicolumn{7}{|l|}{ Interval between meals } \\
\hline Barely adequate/Inadequate & 1.26 & $1 \cdot 13,1.41$ & $<0.001$ & & & \\
\hline \multicolumn{7}{|l|}{ Breakfast skipping } \\
\hline Sometimes/Daily or almost daily & 4.92 & $4 \cdot 22,5 \cdot 74$ & $<0.001$ & 3.66 & $3.02,4.44$ & $<0.001$ \\
\hline \multicolumn{7}{|l|}{ Eating breakfast alone $v$. with others } \\
\hline Alone/Depending on the occasion & 1.36 & $1 \cdot 15,1 \cdot 61$ & $<0.001$ & 1.37 & $1.14,1.63$ & 0.001 \\
\hline \multicolumn{7}{|l|}{ Eating lunch alone $v$. with others } \\
\hline Alone/Depending on the occasion & 1.01 & $0.91,1.13$ & 0.82 & & & \\
\hline \multicolumn{7}{|l|}{ Eating dinner alone $v$. with others } \\
\hline Alone/Depending on the occasion & 1.25 & $1.11,1.39$ & $<0.001$ & & & \\
\hline \multicolumn{7}{|l|}{ Breakfast duration } \\
\hline Barely adequate/Inadequate & 1.59 & $1 \cdot 42,1 \cdot 78$ & $<0.001$ & 1.58 & $1.39,1.79$ & $<0.001$ \\
\hline \multicolumn{7}{|l|}{ Lunch/dinner duration } \\
\hline Barely adequate/Inadequate & 0.71 & $0.64,0.79$ & $<0.001$ & 0.60 & $0.53,0.68$ & $<0.001$ \\
\hline \multicolumn{7}{|l|}{ HEI-2010 } \\
\hline Needs improvement & 1.81 & $1 \cdot 55,2 \cdot 10$ & $<0.001$ & & & \\
\hline \multicolumn{7}{|l|}{ MDS } \\
\hline \multirow{2}{*}{\multicolumn{7}{|c|}{ PA level }} \\
\hline & & & & & & \\
\hline Moderate/Low & 4.00 & $3.50,4.56$ & $<0.001$ & 3.77 & $3.28,4.33$ & $<0.001$ \\
\hline \multicolumn{7}{|l|}{ Sitting time } \\
\hline Inadequate & 1.44 & $1.29,1.60$ & $<0.001$ & & & \\
\hline Alcohol consumption & & & & & & \\
\hline Moderate/High & 0.71 & $0.61,0.81$ & $<0.001$ & 0.51 & $0.44,0.60$ & $<0.001$ \\
\hline Sleep duration per night & & & & & & \\
\hline Barely adequate/Inadequate & 1.20 & $1.08,1.33$ & 0.001 & & & \\
\hline Women (n 15558$)$ & & & & & & \\
\hline No. of EO daily & & & & & & \\
\hline Barely adequate/Inadequate & 1.03 & $0.94,1.13$ & 0.53 & & & \\
\hline Interval between meals & & & & & & \\
\hline Barely adequate/Inadequate & 1.06 & $0.97,1.17$ & 0.22 & & & \\
\hline Breakfast skipping & & & & & & \\
\hline Sometimes/Daily or almost daily & $1 \cdot 16$ & $1.00,1.34$ & 0.05 & & & \\
\hline Eating breakfast alone $v$. with others & & & & & & \\
\hline Alone/Depending on the occasion & 1.79 & $1 \cdot 59,2 \cdot 01$ & $<0.001$ & 1.47 & $1.29,1.66$ & $<0.001$ \\
\hline Eating lunch alone $v$. with others & & & & & & \\
\hline Alone/Depending on the occasion & 1.81 & $1.65,1.99$ & $<0.001$ & 1.42 & $1.27,1.58$ & $<0.001$ \\
\hline Eating dinner alone $v$. with others & & & & & & \\
\hline Alone/Depending on the occasion & 0.91 & $0.81,1.02$ & 0.09 & & & \\
\hline Breakfast duration & & & & & & \\
\hline Barely adequate/Inadequate & 0.94 & $0.86,1.04$ & 0.24 & & & \\
\hline Lunch/dinner duration & & & & & & \\
\hline Barely adequate/Inadequate & 1.33 & $1.21,1.46$ & $<0.001$ & $1 \cdot 31$ & $1 \cdot 18,1.44$ & $<0.001$ \\
\hline HEI-2010 & & & & & & \\
\hline Needs improvement & 0.86 & $0.78,0.96$ & 0.004 & 0.52 & $0.46,0.59$ & $<0.001$ \\
\hline MDS & & & & & & \\
\hline Low adherence & 1.60 & $1.45,1.76$ & $<0.001$ & $2 \cdot 34$ & $2 \cdot 09,2.62$ & $<0.001$ \\
\hline PA level & & & & & & \\
\hline Moderate/Low & 0.64 & $0.57,0.73$ & $<0.001$ & 0.59 & $0.51,0.67$ & $<0.001$ \\
\hline Sitting time & & & & & & \\
\hline Inadequate & 0.72 & $0.65,0.79$ & $<0.001$ & 0.76 & $0.69,0.84$ & $<0.001$ \\
\hline Alcohol consumption & & & & & & \\
\hline Moderate/High & 1.45 & $1.26,1.67$ & $<0.001$ & $2 \cdot 23$ & $1 \cdot 90,2 \cdot 61$ & $<0.001$ \\
\hline Sleep duration per night & & & & & & \\
\hline Barely adequate/Inadequate & 1.71 & $1.56,1.88$ & $<0.001$ & 1.72 & $1.56,1.90$ & $<0.001$ \\
\hline
\end{tabular}

No., number; EO, eating occasions; HEI, Healthy Eating Index; MDS, MedDietScore; PA, physical activity.

* All the variables were dichotomised considering, on the one hand, the healthiest category (that is the reference category in the regression analysis), and, on the other, the intermediate and the least healthy; except for 'sitting time' variable in which the categories were: adequate + barely adequate $v$. inadequate because the frequency for the healthiest category was very low.

† Model 1: effect of each variable adjusted by age and daily energy intake (kcal/d); Model 2: multivariate Wald's test adjusted by age and energy intake. 


\section{Acknowledgements}

The authors also thank the collaboration of the participants and of the students pursuing bachelor's and master's degree who collaborated by performing their internships in the context of this project and contributed to the data curation.

This work was supported by grants from the UPV/EHU (EHU12/24), the Vice Rector for Innovation, Social Outreach and Cultural Activities of the UPV/EHU, funding by the contract-programme formalised with the Basque Government (code of the Campus Bizia Lab project: 17ARRO, 18ARRO and 19ARRO), the Vice Rector for Students and Employability of the UPV/EHU and Basque Government (2016); and a pre-doctoral scholarship from the Basque Language Vice-chancellor of the UPV/EHU. Neither the UPV/EHU nor the Basque Government played a role in the design, analysis or writing of this article.

The author contributions are as follows: N. T.-A. and M. A.-I. contributed to the conception and design of the research, acquired and analysed the data, interpreted the results and finally drafted the manuscript. Both authors read and approved the final manuscript.

There are no conflicts of interest.

\section{Supplementary material}

For supplementary material referred to in this article, please visit https://doi.org/10.1017/S0007114521001483

\section{References}

1. Chung Chooi Y, Ding C \& Magkos F (2019) The epidemiology of obesity. Metabolism 92, 6-10.

2. Global Burden of Disease Collaborative Network (2017) Global Burden of Disease Study 2015 (GBD 2015) Obesity and Overweight Prevalence 1980-2015 [Institute for Health Metrics and Evaluation (IHME), editor]. Seattle. http://ghdx. healthdata.org/record/ihme-data/gbd-2015-obesity-and-over weight-prevalence-1980-2015 (accessed May 2019).

3. Dodd LJ, Al-Nakeeb Y, Nevill A, et al. (2010) Lifestyle risk factors of students: a cluster analytical approach. Prev Med 51, 73-77.

4. Peltzer K, Pengpid S, Samuels TA, et al. (2014) Prevalence of overweight/obesity and its associated factors among university students from 22 countries. Int J Environ Res Public Health 11, S7425-S7441.

5. Vadeboncoeur C, Townsend N \& Charlie Foster Ch (2015) A meta-analysis of weight gain in first year university students: is freshman 15 a myth? BMC Obes $\mathbf{2}, 22$.

6. Gores SE (2008) Addressing nutritional issues in the collegeaged client: strategies for the nurse practitioner. J Amer Acad Nurse Pract 20, 5-10.

7. Sira N \& Pawlak R (2010) Prevalence of overweight and obesity, and dieting attitudes among Caucasian and African American college students in Eastern North Carolina: a cross-sectional survey. Nutr Res Pract 4, 36-42.

8. Pengpid S \& Peltzer K (2014) Prevalence of overweight/obesity and central obesity and its associated factors among a sample of university students in India. Obes Res Clin Pract 8, e558-e570.

9. Zhang Y-X, Wang S-R, Zhao J-S, et al. (2016) Prevalence of overweight and central obesity and their relationship with blood pressure among college students in Shandong, China. Blood Press Monit 21, 251-254.

10. Ruiz E, del Pozo S, Valero T, et al. (2013) Estudio de hábitos alimentarios y estilos de vida de los universitarios españoles (Study of Food Habits and Lifestyles of Spanish University Students). Madrid: Fundación Española de la Nutrición.

11. Ortiz-Moncada R, Norte Navarro AI, Zaragoza Marti A, et al. (2012) ¿Siguen patrones de dieta mediterránea los universitarios españoles? (Do the Spanish University students follow Mediterranean dietary patterns?) Nutr Hosp 27, 1952-1959.

12. Cutillas AB, Herrero E, de San Eustaqui A, et al. (2013) Prevalencia de peso insuficiente, sobrepeso y obesidad, ingesta de energía y perfil calórico de la dieta de estudiantes universitarios de la Comunidad Autónoma de la Región de Murcia (España) (Prevalence of insufficient weight, overweight and obesity, intake of energy and caloric profile of the diet of University students of the Autonomous Community of the Region of Murcia (Spain)). Nutr Hosp 28, S683-S689.

13. Jiang Y, Wang J, Wu S, et al. (2019) Association between takeout food consumption and obesity among chinese university students: a cross-sectional study. Int J Environ Res Public Health 16, 1071.

14. Al Sabbah H (2020) Prevalence of overweight/obesity, anaemia and their associations among female university students in Dubai, United Arab Emirates: a cross-sectional study. J Nutr Sci 9 , e26.

15. Balgoon MJ, Al-Zahrani MH, Alkhattabi NA, et al. (2019) The correlation between obesity and metabolic syndrome in young female university students in the Kingdom of Saudi Arabia. Diabetes Metab Syndr 13, 2399-2402.

16. Colić Barić I, Satalić Z \& Lukesić Z (2003) Nutritive value of meals, dietary habits and nutritive status in Croatian university students according to gender. Int J Food Sci Nutr 54, 473-484.

17. Yahia N, Wang D, Rapley M, et al. (2016) Assessment of weight status, dietary habits and beliefs, physical activity, and nutritional knowledge among university students. Perspect Public Health 136, 231-244.

18. El Ansari W, Stock C \& Mikolajczyk RT (2012) Relationships between food consumption and living arrangements among university students in four European countries-a cross-sectional study. Nutr J 11, 28.

19. Olfert MD, Barr ML, Charlier CC, et al. (2019) Sex differences in lifestyle behaviors among U.S. college Freshmen. Int J Environ Res Public Health 16, 482.

20. Papadaki A, Hondros G, Scott JA, et al. (2007) Eating habits of University students living at, or away from home in Greece. Appetite 49, 169-176.

21. Freedman MR (2010) Gender, residence and ethnicity affect freshman BMI and dietary habits. Am J Health Behav 34, 513-524.

22. Maskarinec G, Namatame LA, Kang M, et al. (2020) Differences in the association of diet quality with body fat distribution between men and women. Eur J Clin Nutr 74, 1434-1441.

23. Assaf I, Brieteh F, Tfaily M, et al. (2019) Students university healthy lifestyle practice: quantitative analysis. Health Inf Sci Syst 7, 7.

24. Schmidt M (2012) Predictors of Self-rated Health and Lifestyle Behaviours in Swedish University Students. Glob J Health Sci 4, 1-14.

25. Hultgren BA, Turrisi R, Cleveland MJ, et al. (2019) Hospital M. Transitions in drinking behaviors across the college years: a latent transition analysis. Addict Behav 92, 108-114.

26. El Ansari W, Ssewanyana D \& Stock C (2018) Behavioral health risk profiles of undergraduate university students in England, wales, and northern Ireland: a cluster analysis. Front Public Health 6, 120. 
27. Hadjimbei E, Botsaris G, Gekas V, et al. (2016) Adherence to the Mediterranean Diet and lifestyle characteristics of university students in cyprus: a cross-sectional survey. J Nutr Metab 2016, 2742841

28. Conklin AI, Forouhi NG, Surtees P, et al. (2014) Social relationships and healthful dietary behaviour: evidence from over-50s in the EPIC cohort, UK. Soc Sci Med 100, 167-175.

29. Johnston JD (2014) Physiological responses to food intake throughout the day. Nutr Res Rev 27, 107-118.

30. Craigie AM, Lake AA, Kelly SA, et al. (2011) Tracking of obesityrelated behaviours from childhood to adulthood: a systematic review. Maturitas 70, 266-284.

31. Laska MN, Lytle LA, Nanney MS, et al. (2016) Results of a 2-year randomized, controlled obesity prevention trial: effects on diet, activity and sleep behaviors in an at-risk young adult population. Prev Med 89, 230-236.

32. Dahm CC, Chomistek AK, Jakobsen MU, et al. (2016) Adolescent diet quality and cardiovascular disease risk factors and incident cardiovascular disease in middle-aged women. J Am Heart Assoc 5, e003583.

33. Kobayashi E, Sato Y, Umegaki K, et al. (2017) the prevalence of dietary supplement use among college students: a nationwide survey in Japan. Nutrients 9, 1250.

34. Barnes K, Ball L, Desbrow B, et al. (2016) Consumption and reasons for use of dietary supplements in an Australian university population. Nutr 32, 524-530.

35. Lieberman HR, Marriott BP, Williams C, et al. (2015) Patterns of dietary supplement use among college students. Clin Nutr $\mathbf{3 4}$, 976-985.

36. Bennasar-Veny M, Yañez AM, Jordi Pericas J, et al. (2020) Cluster Analysis of Health-Related Lifestyles in University Students. Int J Environ Res Public Health 17, 1776.

37. Moreno-Gómez C, Romaguera-Bosch D, Tauler-Riera P, et al. (2012) Clustering of lifestyle factors in Spanish university students: the relationship between smoking, alcohol consumption, physical activity and diet quality. Public Health Nutr 15, 2131-2139.

38. Monneuse MA, Bellisle F \& Koppert G (1997) Eating habits, food and health related attitudes and beliefs reported by French students. Eur J Clin Nutr 51, 46-53.

39. Telleria-Aramburu N, Rocandio AM, Rebato E, et al. (2020) The EHU12/24 cohort: survey design, instruments and participants. Br J Nutr 123, 347-360.

40. Marfell-Jones MJ, Olds T, Stewart AD, et al. (2006) International Standards for Anthropometric Assessment. International Society for the Advancement of Kinanthropometry (ISAK). Potchefstroom, South Africa: ISAK.

41. Durnin JV \& Womersley J (1974) Body fat assessed from total body density and its estimation from skinfold thickness: measurements on 481 men and women aged from 16 to 72 years. Br J Nutr 32, 77-79.

42. Siri WE (1961) Body composition from fluid spaces and density: analysis of methods. In Techniques for Measuring Body Composition, pp. 223-224 [Brozeck J and Henschel A, editors]. Washington, DC: National Academy of Sciences.

43. Bray G, Bouchard C \& James WPT (1998) Definitions and proposed current classifications of obesity. In Handbook of Obesity, pp. 31-40 [Bray GA, Bouchard C \& James WPT, editors]. New York: Marcel Dekker.

44. Bennassar M (2012) Estilos de vida y salud en estudiantes universitarios: La Universidad como entorno promotor de la salud (Lifestyles and health in university students: the university as a promoter of health). Spain: University of Illes Balears.

45. Scott BJ (1997) Baseline nutrition questionnaire. In Obesity assessment: tools, methods, interpretations (a reference case: the Reno Diet-Heart Study), pp. 699-710 [Sachiko T, editor]. New York: Chapman \& Hall series in Clinical Nutrition.

46. Telleria-Aramburu N, Alegria-Lertxundi I \& Arroyo-Izaga M (2021) Adaptation, validation and reproducibility of a short food frequency questionnaire to assess food group intake in the population resident in the Basque Country (Spain). Public Health Nutr 24, 436-448.

47. Leech RM, Worsley A, Timperio A, et al. (2015) Understanding meal patterns: definitions, methodology and impact on nutrient intake and diet quality. Nutr Res Rev $\mathbf{2 8}, 1-21$.

48. Romaguera D, Gracia-Lavedan E, Molinuevo A, et al. (2017) Adherence to nutrition-based cancer prevention guidelines and breast, prostate and colorectal cancer risk in the MCC-Spain Case-Control Study. Int J Cancer 141, 83-93.

49. Sotos-Prieto M, Bhupathiraju SN, Falcon LM, et al. (2015) A healthy lifestyle score is associated with cardiometabolic and neuroendocrine risk factors among Puerto Rican adults. J Nutr 145, 1531-1540.

50. British Nutrition Foundation (2014) Nutrition for a Healthy Living. www.nutrition.org.uk/healthyliving/healthyeating (accessed November 2018).

51. Ma X, Chen Q, Pu Y, et al. (2020) Skipping breakfast is associated with overweight and obesity: a systematic review and meta-analysis. Obes Res Clin Pract 14, 1-8.

52. Bellisle F, Hébel P, Salmon-Legagneur A, et al. (2018) Breakfast consumption in French children, adolescents and adults: a nationally representative cross-sectional survey examined in the context of the International Breakfast Research Initiative. Nutrients 10, 1056

53. Kim CK, Kim H, Chung HK, et al. (2018) Eating alone is differentially associated with the risk of metabolic syndrome in Korean men and women. Int J Environ Res Public Health 15, 1020

54. Estruch R, Martínez-González MA, Corella D, et al. (2016) Effect of a high-fat Mediterranean diet on bodyweight and waist circumference: a prespecified secondary outcome analysis of the PREDIMED randomised controlled trial. Lancet Diabetes Endocrinol 4, 666-676.

55. Collaborative Group of the Spanish Society of Community Nutrition (SENC) (2016) Dietary guidelines for the Spanish population (SENC, December of 2016); the new graphic icon of health nutrition. Nutr Hosp 33, 1-48.

56. Guenther PM, Casavale KO, Reedy J, et al. (2013) Update of the healthy eating index: HEI-2010. J Acad Nutr Diet 113 569-580.

57. Panagiotakos DB, Pitsavos C \& Stefanadis C (2006) Dietary patterns: a Mediterranean diet score and its relation to clinical and biological markers of cardiovascular disease risk. Nutr Metab Cardiovasc Dis 16, 559-568.

58. International Physical Activity Questionnaire (IPAQ) (2006) Guidelines for Data Processing and Analysis of the International Physical Activity Questionnaire (IPAQ) - Short Form. http:// www.institutferran.org/documentos/Scoring_short_ipaq_april04. pdf (accessed August 2010).

59. Jelsma JGM, Gale J, Loyen A, et al. (2019) Time trends between 2002 and 2017 in correlates of self- reported sitting time in European adults. PLoS One 14, e0225228.

60. Warren TY, Barry V, Hooker SP, et al. (2010) Sedentary behaviors increase risk of cardiovascular disease mortality in men. Med Sci Sports Exerc 42, 879-885.

61. Spanish Society of Community Nutrition (SENC) \& Spanish Society of Family and Community (semFYC) (2007) Consejos para una Alimentación Saludable (Tips for Healthy Eating). Madrid, Spain: SENC y semFYC. 
62. Hirshkowitz M, Whiton K, Albert SM, et al. (2015) National Sleep Foundation's sleep time duration recommendations: methodology and results summary. Sleep Health 1, 40-43.

63. Carbajal A \& Sánchez-Muniz FJ (2003) Guía de prácticas (Practice guide). In Nutrición y Dietética (Nutrition and Dietetics), pp. 1-130 [García-Arias MT \& García- Fernández MC, editors]. León, Spain: Secretariado de Publicaciones y Medios Audiovisuales, Universidad de León.

64. Departamento de Agricultura \& Pesca y Alimentación, Gobierno Vasco (2008) Estudio cuantitativo del consumo de alimentos en la CAPV. Guia Elika (Quantitative Study of the Consumption of Food in the Basque Country. Elika Guide). Vitoria-Gasteiz, Spain: Basque Government.

65. Ortega RM, López-Sobaler AM, Andrés P, et al. (2016) DIAL software for assessing diets and food calculations (for Windows, version 2.12). Madrid, Spain: Department of Nutrition (UCM) \& Alce Ingeniería.

66. Panagiotakos DB, Milias GA, Pitsavos C, et al. (2006) MedDietScore: a computer program that evaluates the adherence to the Mediterranean dietary pattern and its relation to cardiovascular disease risk. Comput Meth Prog Bio 83, 73-77.

67. García-Meseguer MJ, Cervera F, Vico C, et al. (2014) Adherence to Mediterranean diet in a Spanish university population. Appetite 78, 156-164.

68. Ministry of Health, Consumption and Social Well-being \& Government of Spain (2006) Encuesta Nacional de Salud de España (National Health Survey of Spain). https://www. mscbs.gob.es/estadEstudios/estadisticas/encuestaNacional/ encuesta2006.htm (accessed August 2010).

69. Ministerio de Sanidad y Consumo (2017) Informes de la Comisión Clínica. Alcohol (Reports of the Clinical Commission. Alcohol). http://www.pnsd.msc.es/Categoria2/publica/pdf/ InformeAlcohol.pdf (accessed July 2017).

70. Kim JH (2017) Sleep duration and obesity. J Obes Metab Syndr 26, $1-2$.

71. Traversy G \& Chaput JP (2015) Alcohol consumption and obesity: an update. Curr Obes Rep 4, 122-130.

72. Healton CG, Vallone D, McCausland KL, et al. (2006) Smoking, obesity, and their co-occurrence in the United States: cross sectional analysis. BMJ 333, 25-26.

73. Patel K, Hargreaves MK, Liu J, et al. (2011) Relationship between smoking and obesity among women. Am J Health Behav 35, 627-636.

74. University of the Basque Country, UPV/EHU (2013) Students enrolled, 2012-2013 school year. http://www.ehu.es/ zenbakitan/es/node/17.html (accessed September 2013).

75. Basque Govern (2018) Encuesta de Salud (Health Survey) http://www.euskadi.eus/informacion-encuesta-salud-2018tablas-de-resultados/web01-a3osag17/es/ (accessed November 2020).
76. Zaccagni L, Barbieri D \& Gualdi-Russo E (2014) Body composition and physical activity in Italian university students. J Transl Med 12, 120

77. Hearty AP, McCarthy SNL, Kearney JM, et al. (2007) Relationship between attitudes toward healthy eating and dietary behaviour, lifestyle and demographic factors in a representative sample of Irish adults. Appetite 48, 1-11.

78. Kant AK \& Graubard BI (2015) 40-year trends in meal and snack eating behaviours of American adults. J Acad Nutr Diet $\mathbf{1 1 5}$, S50-S63.

79. Jaalouk D, Matar Boumosleh J, Helou L, et al. (2019) Dietary patterns, their covariates, and associations with severity of depressive symptons among university students in Lebanon: a cross-sectional study. Eur J Nutr 58, 997-1008.

80. García-Meseguer MJ, Delicado-Soria A \& Serrano-Urrea R (2017) Fiber patterns in young adults living in different environments (USA, Spain, Tunisia). Anthropometric and lifestyle characteristics. Nutrients $\mathbf{9}, 1030$.

81. Davoren MP, Demant J, Shiely F, et al. (2016) Alcohol consumption among university students in Ireland and the United Kingdom from 2002 to 2014: a systematic review. BMC Public Health 16, 173.

82. Shang MJ, Zou YF, Guo P, et al. (2019) Systematic estimation of BMI. A novel insight into predicting overweight/obesity in undergraduates. Medicine $\mathbf{9 8}$, e15810.

83. Lee Y, Cho W \& Oh Y (2012) Comparison of eating behavior between commensality and solo-eating of university students by BMI. Korean J Community Nutr 17, 280-289.

84. Whatnall MC, Patterson AJ, Brookman S, et al. (2019) Lifestyle behaviors and related health risk factors in a sample of Australian university students. J Am Coll Health 68, 734-741.

85. Holmbäck I, Ericson U, Gullberg B, et al. (2010) A high eating frequency is associated with an overall healthy lifestyle in middle-aged men and women and reduced likelihood of general and central obesity in men. Br J Nutr 104, 1065-1073.

86. Trost SG, Pate RR, Sallis JF, et al. (2002) Age and gender differences in objectively measured physical activity in youth. Med Sci Sport Exerc 34, 350-355.

87. Haynes A, Kersbergen I, Sutin A, et al. (2018) A systematic review of the relationship between weight status perceptions and weight loss attempts, strategies, behaviours and outcomes. Obes Rev 19, 347-363.

88. Vereecken CA, Covents M, Sichert-Hellert W, et al. (2008) Development and evaluation of a self-administered computerized 24-h dietary recall method for adolescents in Europe. Int J Obes 32, S26-S34.

89. Bayyari WD, Henry LJ \& Jones C (2013) Dieting Behaviours, Obesity and predictors of dieting among female college students at Palestinian universities. East Mediterr Health J 19, 30-36. 